\title{
LC methods for acyclovir and related impurities determination
}

\author{
A.L. Huidobro, F.J. Rupérez, C. Barbas* \\ Sección de Química Analítica, Facultad de CC Experimentales y de la Salud, Urbanización Montepríncipe, 28668 Boadilla del Monte, Madrid, Spain
}

Received 30 July 2004; received in revised form 16 November 2004; accepted 17 November 2004

Available online 4 January 2005

\begin{abstract}
Acyclovir, guanine, and impurity A have been baseline separated with isocratic conditions at $\mathrm{pH}=3.0$ and run time under $15 \mathrm{~min}$ by employing a SB-CN column from Agilent $(150 \mathrm{~mm} \times 4.6 \mathrm{~mm}$ and $3.5 \mu \mathrm{m})$. Moreover, when run time was increased to $40 \mathrm{~min}$ six impurities (guanine, impurities A, F, G, Vir 3/4 and $\mathrm{N}^{7}$ ) plus acyclovir were separated in the same conditions. The mobile phase consisted of buffer A/acetonitrile 96:4 (v/v), being buffer A:25 $\mathrm{mM} \mathrm{H}_{3} \mathrm{PO}_{4}$ (Milli-Q $\mathrm{H}_{2} \mathrm{O}$ ) brought to $\mathrm{pH} 3.0$ with $\mathrm{KOH}$.

The same column provided separation for all the seven impurities described in pharmacopoeia, including impurity $\mathrm{C}$, which coeluted with acyclovir in the previous conditions with a mobile phase prepared with $25 \mathrm{mM}$ phosphoric acid $(\mathrm{pH}=1.8) /$ acetonitrile $96: 4(\mathrm{v} / \mathrm{v})$.

The method has been validated following ICH guidelines and it has demonstrated to be reliable for acyclovir and its impurities determination. (C) 2004 Elsevier B.V. All rights reserved.
\end{abstract}

Keywords: HPLC; Acyclovir; Cyano stationary phase

\section{Introduction}

Acyclovir is a synthetic purine nucleoside analogue with in vitro and in vivo inhibitory activity against herpes simplex virus and varicella-zoster virus. It is a white to off-white crystalline powder with molecular weight of 225.21 and solubility in water below $2.5 \mathrm{mg} / \mathrm{ml}$ at $37^{\circ} \mathrm{C}$. Acyclovir $\mathrm{p} K_{\mathrm{a}}$ are 2.27 and 9.25 [1].

Acyclovir determination in pharmaceuticals has been performed spectrophotometrically. A visible spectrophotometric method, not very sensitive [2], a derivative spectrophotometric [3] and a differential spectrophotometric method [4] have been proposed.

The more common technique is HPLC with UV detection [5-7] or coupled to MS [8,9]. Nevertheless, none of these methods include related compounds more than guanine.

The related compounds to be determined following the Pharmacopeias are guanine and impurity A (acetate form of acyclovir), but the bulk material can present at least seven

\footnotetext{
* Corresponding author. Tel.: +34 91 3724711; fax: +34 913510475.

E-mail address: cbarbas@ceu.es (C. Barbas).
}

impurities all of them with similar structures as can be seen in Fig. 1. The presence of these impurities can be important not only for quality control, but also in enforcing patent rights because they can be route indicative of the synthesis of acyclovir.

Only one method in literature includes three of these impurities plus acyclovir [10]. Authors say that it is difficult to quantitate, because it employs liquid extraction and HPLC with fraction collection with further analysis by mass spectrometry.

As guanine and acyclovir are very polar and easily ionizable, they are usually separated in reverse phase with ionpairing chromatography at acidic $\mathrm{pH}$ using decanosulfonate [11]. The drawbacks of ion-pairing chromatography are generally known: a long equilibration time; as the ion pairing compounds interact strongly with the stationary phase, they are difficult to eliminate from the column after their use, and they provide poor migration time reproducibility. The last is a very undesirable point during a stability indicating assay.

The availability of new stationary phases with new selectivities in reverse phase HPLC provided us with the possibility of new separations avoiding these drawbacks. There- 
<smiles>Nc1nc2c(ncn2COCCO)c(=O)[nH]1</smiles>

Acyclovir<smiles>Nc1nc2ncn(COCCO)c2c(=O)[nH]1</smiles>

Impurity C<smiles>O=C(Nc1nc2c(ncn2COCCO)c(=O)[nH]1)C1CCCCC1</smiles>

Impurity F<smiles>Nc1nc2c(ncn2CC(=O)CCC(=O)Cn2cnc3c(=O)[nH]c(N)nc32)c(=O)[nH]1</smiles>

Impurity VIR $3 / 4$<smiles>Nc1nc2[nH]cnc2c(=O)[nH]1</smiles>

Guanine<smiles>CC(=O)OCCOCn1cnc2c(=O)[nH]c(N)nc21</smiles>

Impurity A<smiles>CC(=O)Nc1nc2c(ncn2COCCOC(=O)O)c(=O)[nH]1</smiles>

Impurity G<smiles>CC(=O)OCCOCn1cnc2nc(NC(=O)C3CCCCC3)[nH]c(=O)c21</smiles>

Impurity $\mathrm{N}^{\top}$

Fig. 1. Chemical structures of the assayed compounds.

fore, the objective of this work was the exploration of HPLC columns for the separation of acyclovir impurities avoiding ion-pairing reagents.

\section{Experimental}

\subsection{Apparatus}

LaChrom Elite HPLC equipment from VWR consisted of quaternary pump, an automatic injector, a single wavelength detector and a column oven. Different columns and mobile phases were tested. Finally, the method was validated with a SB-CN column from Agilent $(150 \mathrm{~mm} \times 4.6 \mathrm{~mm}$ and $3.5 \mu \mathrm{m}$ ). It provided baseline separation with isocratic conditions at $\mathrm{pH}=3.0$ and run time under $15 \mathrm{~min}$ for guanine, acyclovir and impurity A. Moreover, when run time was increased to $40 \mathrm{~min}$ six impurities (guanine, impurities A, F, G, Vir 3/4 and $\mathrm{N}^{7}$ ) plus acyclovir could be separated in the same conditions. The mobile phase consisted of buffer A/acetonitrile 96:4 (v/v), being buffer A:25 mM $\mathrm{H}_{3} \mathrm{PO}_{4}$ brought to $\mathrm{pH} 3.0$ with $\mathrm{KOH}$. The oven temperature was $35^{\circ} \mathrm{C}$ and $\mathrm{UV}$ detection was performed at $254 \mathrm{~nm}$. 
The same column provided separation for all the seven impurities, including impurity $\mathrm{C}$, which coeluted with acyclovir in the previous conditions with a mobile phase prepared with $25 \mathrm{mM}$ phosphoric acid $(\mathrm{pH}=1.8) /$ acetonitrile $96: 4(\mathrm{v} / \mathrm{v})$.

\subsection{Chemicals}

Standard of acyclovir and impurities (impurity A, impurity C, impurity F, impurity G, impurity Vir $3 / 4$, impurity $\mathrm{N}^{7}$ ) as well as tablets and excipients (silicon dioxide, talc, magnesium stearate, povidone ${ }^{\circledR}$, avicel ${ }^{\circledR}$, primogel ${ }^{\circledR}$ ) were kindly provided by CINFA S.A. (Pamplona, Spain). Guanine was purchased from Sigma-Aldrich (Steinheim, Germany), $\mathrm{NaOH}(>99 \%)$ was from Panreac (Barcelona, Spain), $\mathrm{H}_{3} \mathrm{PO}_{4}$ (85\%) and $\mathrm{CH}_{3} \mathrm{CN}$ (HPLC grade) were from Merck (Darmstadt, Germany) and water was purified with a Milli-Q plus system from Millipore (Bedford, MA, USA).

\subsection{Standard solutions and sample preparation}

In all cases the solvent solution (SS) for standards and samples was the mobile phase phosphate buffer $25 \mathrm{mM} \mathrm{pH}$ 3.0/acetonitrile 96:4 (v/v). Acyclovir standard solution was prepared with $40.0 \mathrm{mg}$ of acyclovir exactly weighed and dissolved with SS in a $100 \mathrm{ml}$ volumetric flask.

All the impurities were individually prepared with $10 \mathrm{mg}$ exactly weighed and dissolved in $250 \mathrm{ml}$ volumetric flasks with SS, except for guanine and impurity Vir 3/4, which needed $25 \mathrm{ml}$ of $\mathrm{NaOH}(0.1 \mathrm{~N})$. An intermediate solution containing all the impurities was prepared with $0.2 \mathrm{ml}$ of each impurity stock solution, all together, made up $10 \mathrm{ml}$ with SS.

For quantification $53.73 \mathrm{mg}$ of the pulverised tablets were made up to $100 \mathrm{ml}$ with SS. After bath sonication for around 5 min samples were filtered with $0.45 \mu \mathrm{m}$ nylon filters prior to the injection.

\subsection{Validation}

The selectivity was tested by running solutions containing the excipients of the speciality in the same quantities and conditions that the samples to show that there was no peak at the retention times corresponding to the analytes. Moreover, solutions of the standards with the identified impurities at the $0.2 \%$ level added were also run to show the resolution and selectivity of the method.

Validation parameters were tested in two ranges: quantification range and impurities range. The linearity was tested for the high range by preparing standard solutions at five concentration levels, from $75 \%$ to $120 \%$ of the target analyte concentration. In this case, acyclovir concentrations were from $0.3 \mathrm{mg} / \mathrm{ml}$ to $0.48 \mathrm{mg} / \mathrm{ml}$. They were prepared in $100 \mathrm{ml}$ volumetric flasks by weighting the exact amount of acyclovir (from $30 \mathrm{mg}$ to $48 \mathrm{mg}$ ) and completed the total volume with SS. Each point was analysed three times.

For the low range, acyclovir concentrations ranged from $0.2 \mu \mathrm{g} / \mathrm{ml}$ to $4 \mu \mathrm{g} / \mathrm{ml}$ while guanine concentrations were from
$0.2 \mu \mathrm{g} / \mathrm{ml}$ to $20 \mu \mathrm{g} / \mathrm{ml}$, they were prepared in $10 \mathrm{ml}$ volumetric flasks by adding the corresponding volumes of acyclovir and guanine stock standard $(0.050-1.00 \mathrm{ml}$ for acyclovir and $0.050-2.5 \mathrm{ml}$ for guanine) and completed the total volume with SS.

For pharmaceutical studies in drug products one method for determining accuracy is the application of the analytical procedure to synthetic mixtures of the drug components to which known quantities of the drug substances to be analysed have been added. It was tested in triplicate at three levels $(80$, 100 and $110 \%$ ) and in parallel with the linearity assay for the two main components. The percent recovery and the R.S.D were then calculated.

For accuracy in the low range, $7.0 \mathrm{mg}$ of excipients were weighted in $50 \mathrm{ml}$ volumetric flasks and the corresponding volumes of acyclovir stock solution were added to obtain $0.05,0.1,0.2,0.5$ and $1.0 \%$ and $0.05,0.2,0.5,1.0$ and $5.0 \%$ for guanine. These ranges included from the limit of declaration to a value over the limit of acceptance.

Intra-assay precision data were obtained by repeatedly analysing, in one laboratory on 1 day, 10 aliquots of an homogeneous sample (for the high range) and six aliquots (for the low range), each of which were independently prepared according to the method procedure and the corresponding standards. Data for intermediate precision were obtained by repeating the intra-assay experiment on a different day with newly prepared solutions.

The detection limit (LOD) was evaluated by measuring the baseline noise and by calculating the analyte concentration that gives $\mathrm{S} / \mathrm{N}=3$, while the limit of quantification (LOQ) was established for the analyte concentration that gives $\mathrm{S} / \mathrm{N}=10$. Nevertheless, that is an approach, because the actual LOQ was established by validating the method to the lower level.

Response factors for impurities A, F, G, Vir 3/4, and $\mathrm{N}^{7}$, relative to acyclovir, were calculated by running ten times a mixture containing the impurities plus acyclovir at $0.2 \%$.

Standard stability was tested by running the same sample corresponding to the medium point in the linearity assay for 0-3 days and with the same mobile phase. Between runs, solutions were stored at ambient temperature. The initial area was considered $100 \%$ and recoveries in the following days were evaluated.

\section{Results and discussion}

In order to obtain an adequate resolution in isocratic conditions without employing ion-pairing reagents several stationary phases and $\mathrm{pHs}$ in the mobile phase were tested. New stationary phases compatible with $100 \%$ aqueous mobile phases and polar reverse phase stationary phases, such as polyethyleneglycol or cyano may help to avoid using gradient elution when separating a mixture of compounds with widely varying concentrations. They provide a balance of retention for polar and non-polar compounds in reversedphase chromatography with higher retention for more po- 


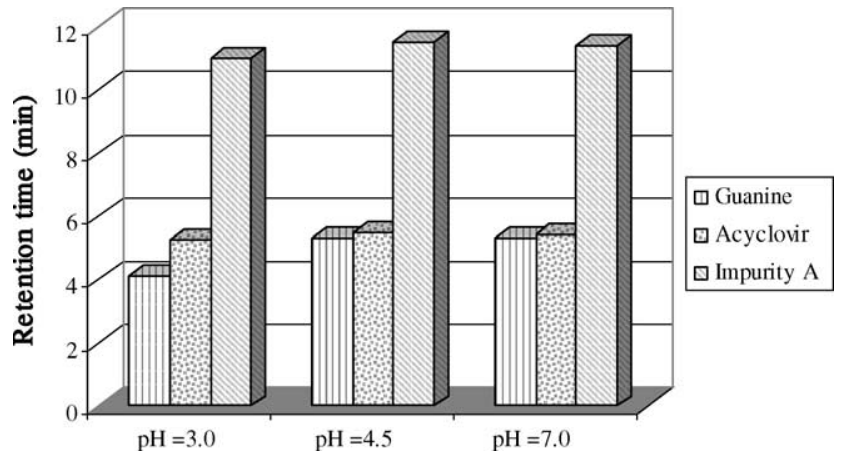

Fig. 2. Influence of mobile phase $\mathrm{pH}$ in the separation of acyclovir, guanine and impurity A. The column was SB-CN Agilent $150 \mathrm{~mm} \times 4.6 \mathrm{~mm}, 3.5 \mu \mathrm{m}$. Mobile phase phosphate buffer $25 \mathrm{mM} /$ acetonitrile 95:5 (v/v). UV detection at $254 \mathrm{~nm}$.

lar compounds while lower retention to more hydrophobic compounds. Therefore, different columns were tested in this line: Atlantis ${ }^{\mathrm{TM}} \mathrm{dC} 18$ (Waters) $5 \mu \mathrm{m}, 4.6 \mathrm{~mm} \times 250 \mathrm{~mm}$, a silica-based line of difunctionally bonded $\mathrm{C} 18$ columns; Zorbax SB C18 Aq $5 \mu \mathrm{m}, 3.0 \mathrm{~mm} \times 150 \mathrm{~mm}$ and a Discovery cyanopropyl $5 \mu \mathrm{m}, 4.6 \mathrm{~mm} \times 250 \mathrm{~mm}$ (Supelco), the bonded phase is $-\mathrm{O}-\mathrm{Si}\left(\mathrm{CH}_{3}\right)_{2} \mathrm{CH}_{2} \mathrm{CH}_{2} \mathrm{CH}_{2} \mathrm{CN}$, it is endcapped and has a pore size of $180 \AA$. Some of the characteristics according to the manufacturer are the low hydrophobicity for rapid elution of hydrophobic molecules, the retention and separation of strongly basic analytes, the compatibility with highly percent of aqueous mobile phases and its excellent stability and reproducibility. It has been previously described that the properties of the CN columns are governed by the type of cyano phase (trifunctional or monofunctional) on the silica gel support and endcapping $[12,13]$. Therefore, a very different column was tested. Agilent Zorbax SB-CN is described by the manufacturer as a densely covered, sterically protected, diisopropyl cyanopropyl stationary phase, not endcapped, with pore size of $80 \AA$. This column was assayed in two sizes: the classical $5 \mu \mathrm{m}, 4.6 \mathrm{~mm} \times 250 \mathrm{~mm}$ column, and another one with lower particle diameter and length, considered equiv- alent and named by manufacturers as "solvent saver" with $3.5 \mu \mathrm{m}, 4.6 \mathrm{~mm} \times 150 \mathrm{~mm}$. Finally, polyethyleneglycol PEG (Supelco) $5 \mu \mathrm{m}, 4.6 \mathrm{~mm} \times 250 \mathrm{~mm}$, was also tested.

All the columns assayed can be considered equivalent in dimensions, although working at a different flow rates: $1 \mathrm{ml} / \mathrm{min}$ for $5 \mu \mathrm{m}, 4.6 \mathrm{~mm} \times 250 \mathrm{~mm}$ columns and $0.6 \mathrm{ml} / \mathrm{min}$ for $3.5 \mu \mathrm{m}, 4.6 \mathrm{~mm} \times 150 \mathrm{~mm}$ columns.

The first assay was to study the effect of mobile phase $\mathrm{pH}$. Different columns were checked at 90:10 and 95:5 (v/v) $25 \mathrm{mM}$ phosphate buffer/acetonitrile. Phosphate buffer was employed at $\mathrm{pH}=3.0,4.5$, and 7.0. Preliminary assays were developed only with guanine, acyclovir and impurity A, which are those included in Pharmacopoeia methods. Fig. 2 shows the result for Agilent Zorbax SB-CN, and similar trends were observed in most of the columns, that is resolution increases at $\mathrm{pH}=3.0$ because guanine retention decreases slightly. It can be justified with the $\mathrm{p} K_{\mathrm{a}}=3.30$ for guanine [14], because at lower $\mathrm{pH}$ the nitrogen gets a proton and the ionised form is less retained, meanwhile the equivalent nitrogen in acyclovir has a $K_{\mathrm{a}}=2.01$.

The results for 95:5 (v/v) $25 \mathrm{mM}$ phosphate buffer $\mathrm{pH}$ 3.0/acetonitrile are shown in Fig. 3. Polyethyleneglycol PEG and $\mathrm{CN}$ columns from Supelco were discarded because they did not provide enough resolution in these conditions. Zorbax SB-Aq and C18 from Agilent were also discarded because guanine was too near to the dead volume. Atlantis column from Waters showed good resolution, but too high retention time for impurity A, and therefore, a gradient seemed necessary. The best ratio and values in migration times was for SB$\mathrm{CN}$ columns from Agilent. Moreover, it was experimentally confirmed that the two dimensions $5 \mu \mathrm{m}, 4.6 \mathrm{~mm} \times 250 \mathrm{~mm}$ and $3.5 \mu \mathrm{m}, 4.6 \mathrm{~mm} \times 150 \mathrm{~mm}$ provided almost the same retention times, but working at $1.0 \mathrm{ml} / \mathrm{min}$ and $0.6 \mathrm{ml} / \mathrm{min}$ respectively, and therefore, the waste of a higher solvent amount is useless.

All the impurities were then injected in the SB-CN from Agilent. Fig. 4 shows the separation obtained for all the standards at $0.2 \%$ level. As can be seen, impurity $\mathrm{C}$ and acyclovir

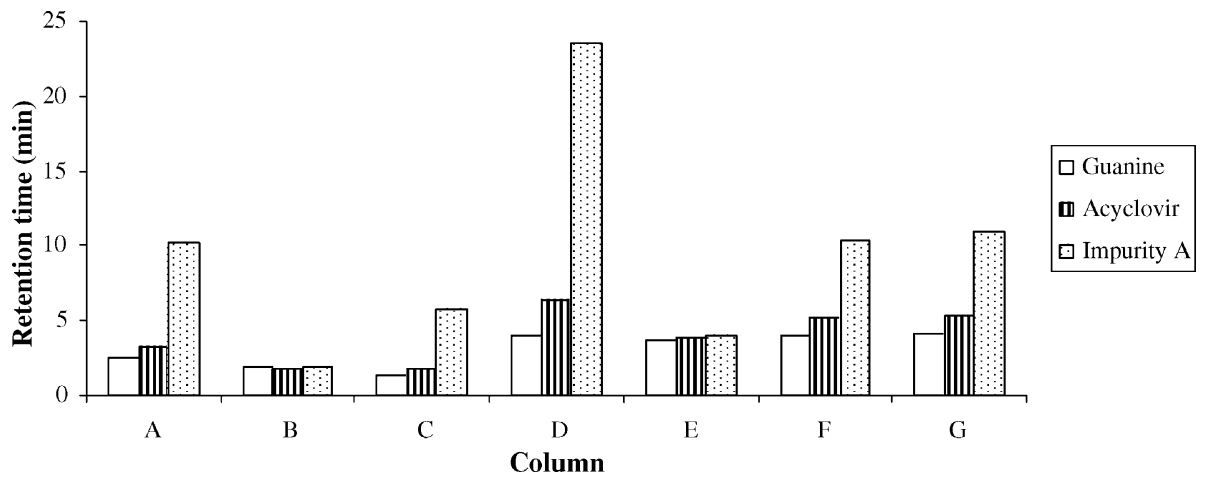

Fig. 3. Comparative behaviour of acyclovir, guanine and impurity A on different stationary phases. Chromatographic conditions: phosphate buffer $25 \mathrm{mM}$ $\mathrm{pH}=3.0 /$ acetonitrile $95: 5(\mathrm{v} / \mathrm{v})$. UV detection at $254 \mathrm{~nm}$. Column: (A) Agilent Zorbax Eclipse XDB C $18150 \mathrm{~mm} \times 4.6 \mathrm{~mm}, 3.5 \mu \mathrm{m}$, flow rate $0.6 \mathrm{ml} / \mathrm{min}$; (B) Supelco PEG $150 \mathrm{~mm} \times 4.6 \mathrm{~mm}, 5 \mu \mathrm{m}$, flow rate $1.0 \mathrm{ml} / \mathrm{min}$; (C) Agilent Zorbax SB-Aq $150 \mathrm{~mm} \times 3 \mathrm{~mm}, 5 \mu \mathrm{m}$, flow rate $1.0 \mathrm{ml} / \mathrm{min}$; (D) Waters Atlantis $250 \mathrm{~mm} \times 4.6 \mathrm{~mm}, 5 \mu \mathrm{m}$, flow rate $1.0 \mathrm{ml} / \mathrm{min}$; (E) Supelco CN $250 \mathrm{~mm} \times 4.6 \mathrm{~mm}, 5 \mu \mathrm{m}$, flow rate $1.0 \mathrm{ml} / \mathrm{min}$; (F) Agilent CN $250 \mathrm{~mm} \times 4.6 \mathrm{~mm}, 5 \mu \mathrm{m}$, flow rate $1.0 \mathrm{ml} / \mathrm{min}$; (G) Agilent $\mathrm{CN} 150 \mathrm{~mm} \times 4.6 \mathrm{~mm}, 3.5 \mu \mathrm{m}$, flow rate $0.6 \mathrm{ml} / \mathrm{min}$. 


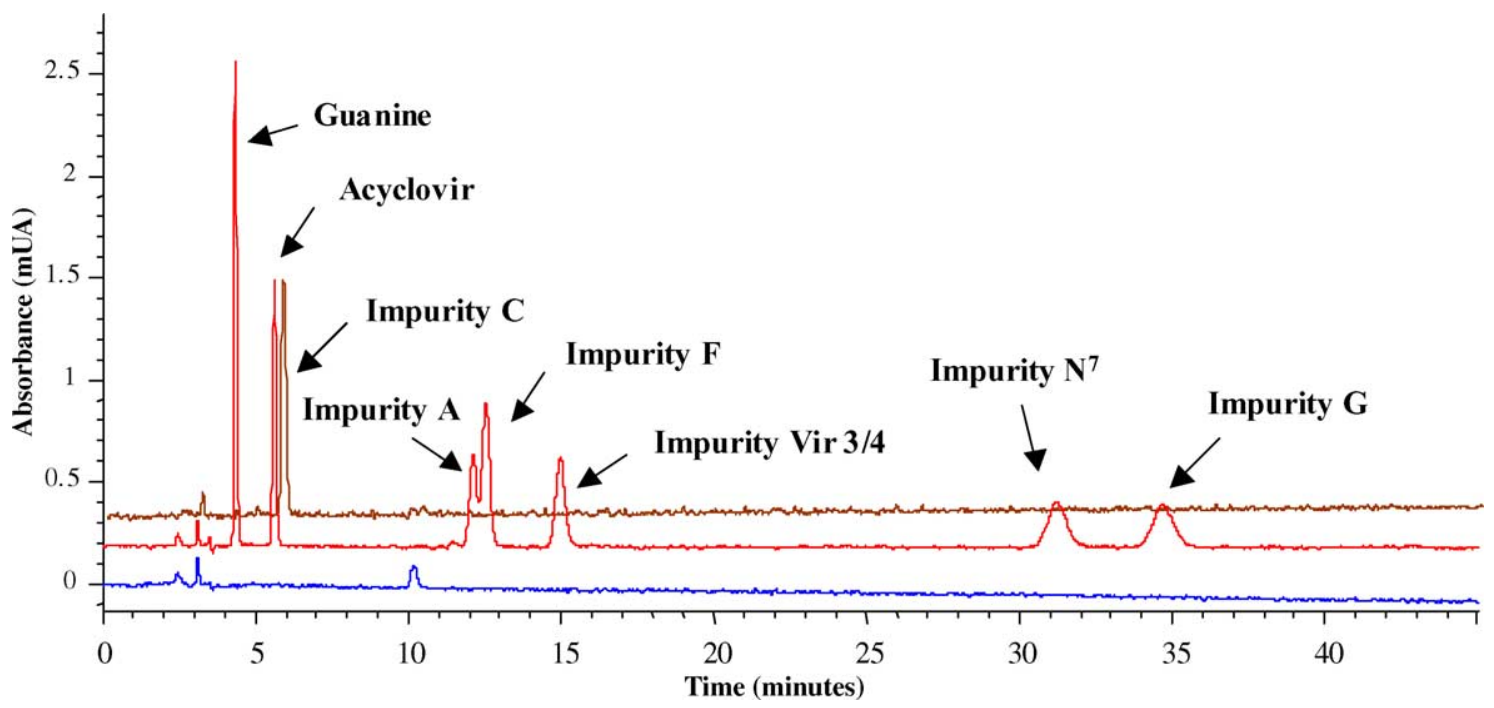

Fig. 4. Chromatogram showing acyclovir $(0.4 \mathrm{mg} / \mathrm{ml})$ and related impurities (all of them $0.2 \%$ of the main peak) separation. Agilent Cyano column, $3.5 \mu \mathrm{m}$ particle size, $150 \mathrm{~mm} \times 4.6 \mathrm{~mm}$ kept at $35^{\circ} \mathrm{C}$. The mobile phase consisted of phosphate buffer $25 \mathrm{mM}(\mathrm{pH}=3.0) /$ acetonitrile $96: 4(\mathrm{v} / \mathrm{v})$. Flow rate, $0.6 \mathrm{ml} / \mathrm{min}$ and UV detection, $254 \mathrm{~nm}$. The lower line corresponds to the excipients.

coeluted in these conditions and increasing the water amount to $100 \%$ did not improve the result.

Looking at the $\mathrm{p} K_{\mathrm{a}}$ values it could be thought that under $\mathrm{pH} 2$ a new protonation of a nitrogen could occur with the corresponding change in retention times that could produce some differentiation. Therefore, we tested 96:4 (v/v) $25 \mathrm{mM}$ phosphoric acid ( $\mathrm{pH} 1.8$ )/acetonitrile with SB-CN column, which is described as stable in these conditions. Fig. 5 shows the separation obtained with impurity $\mathrm{C}$ separated from acyclovir and impurity Vir 3/4 eluting at shorter retention time. Nevertheless, as impurity $\mathrm{C}$ comes from the synthesis, but it is not a degradation product, we decided to discard its presence in the raw material at $\mathrm{pH} 1.8$, as can be seen in Fig. 6, but to validate the method at $\mathrm{pH} 3.0$, which is less aggressive for

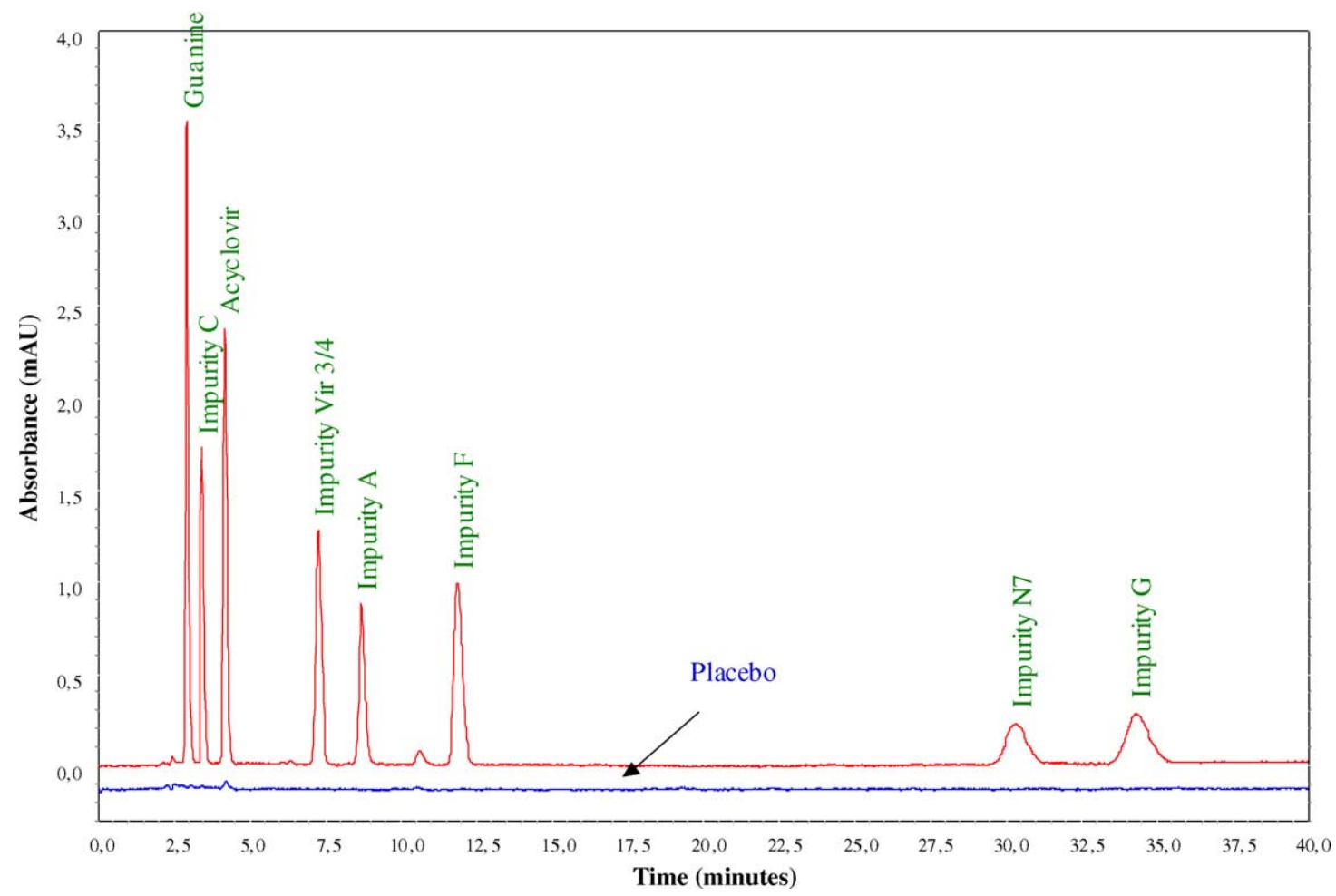

Fig. 5. Chromatogram of acyclovir $(0.4 \mathrm{mg} / \mathrm{ml})$ and related impurities, all of them at $0.2 \%$. Column SB-CN Agilent, $3.5 \mu \mathrm{m}, 150 \mathrm{~mm} \times 4.6 \mathrm{~mm}$. Mobile phase phosphate buffer $25 \mathrm{mM}(\mathrm{pH}=1.8) /$ acetonitrile $96: 4(\mathrm{v} / \mathrm{v})$. Flow rate, $0.6 \mathrm{ml} / \mathrm{min}$, UV detection at $254 \mathrm{~nm}$. 


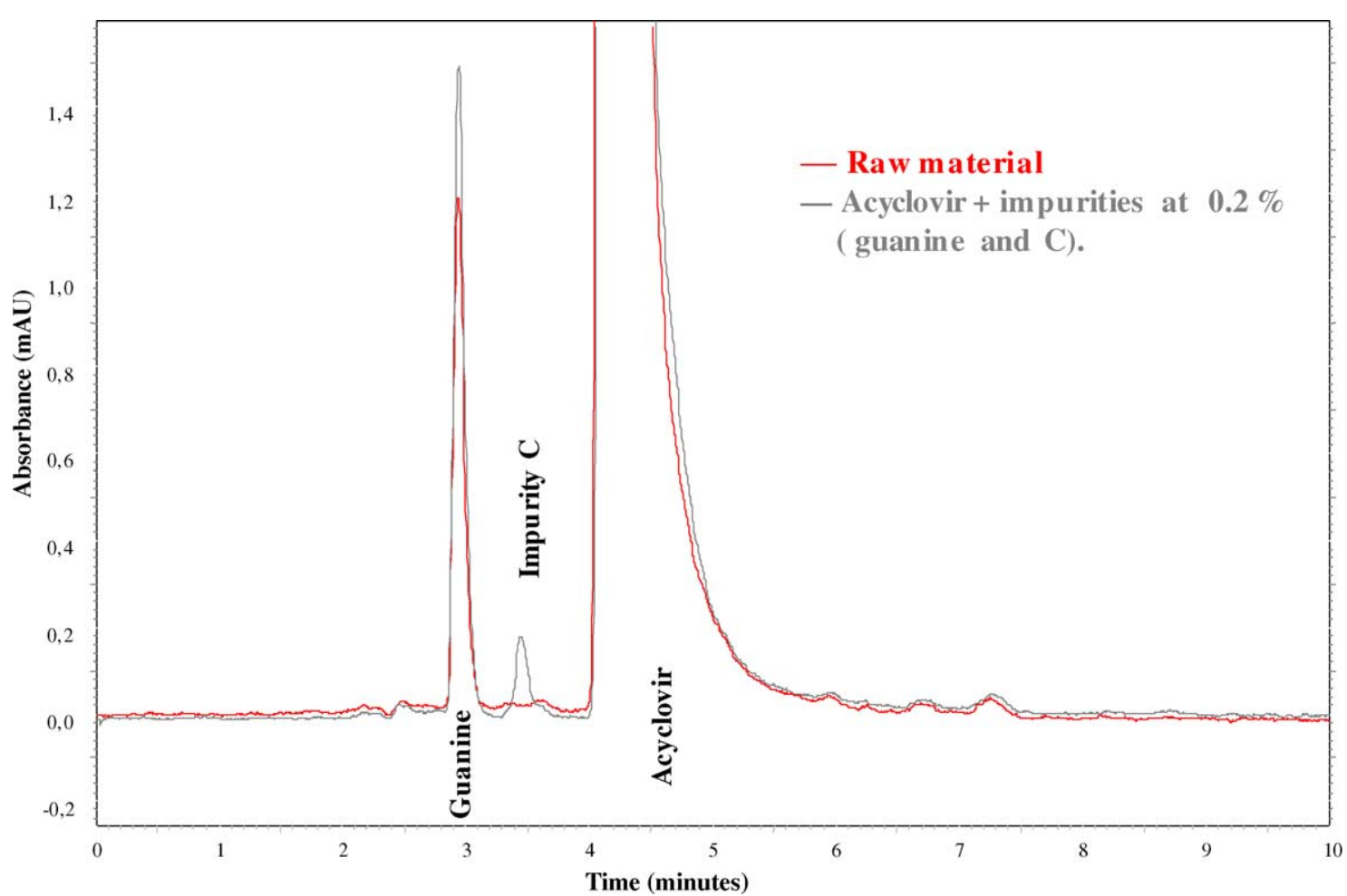

Fig. 6. Chromatograms corresponding to: (a) acyclovir and impurities at $0.2 \%$ (guanine and C); (b) Raw material at $100 \%$.

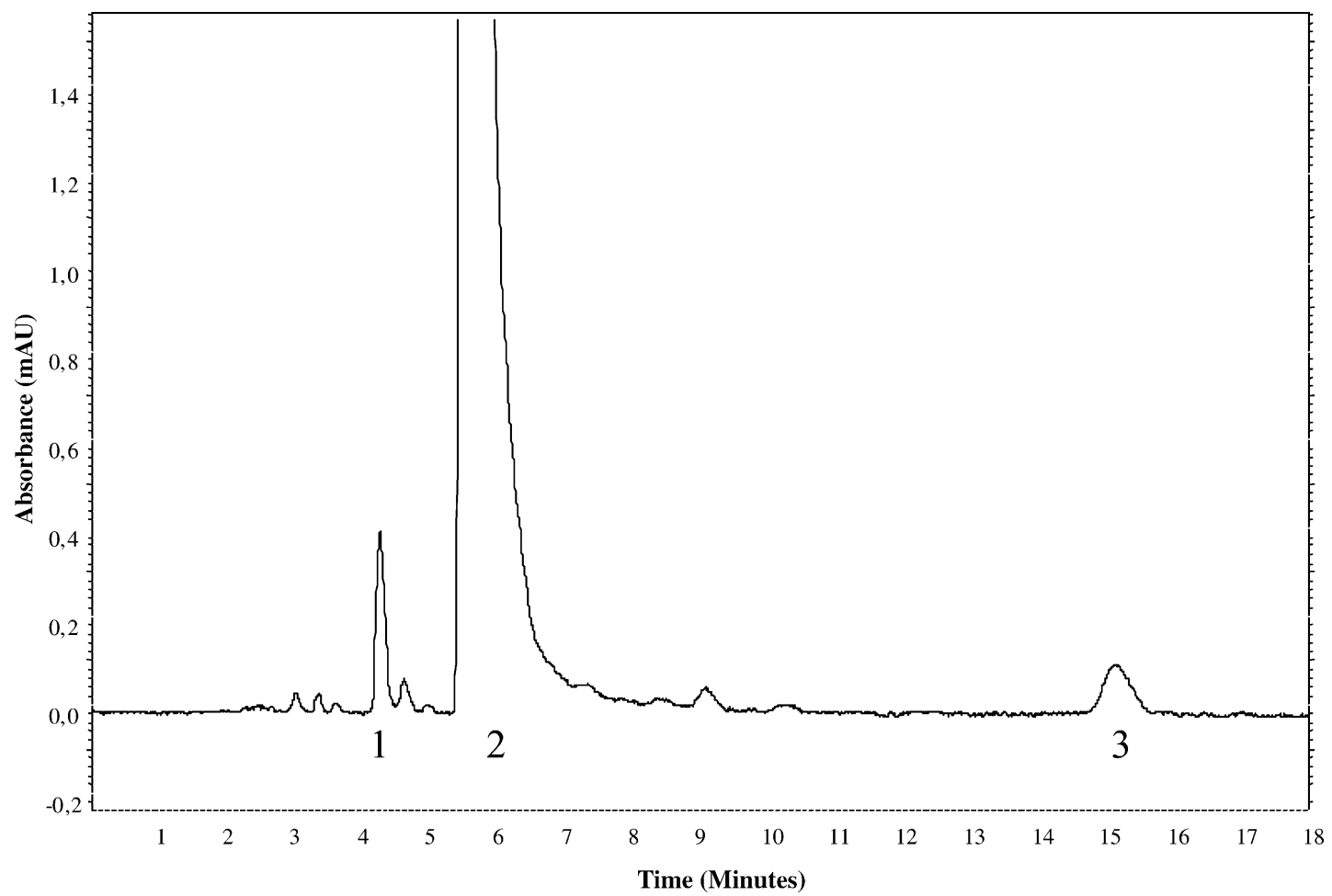

Fig. 7. Chromatogram corresponding to a tablet of acyclovir at the quantification level. Peak identification 1: guanine, 2: acyclovir, 3: impurity Vir 3/4. Conditions: Agilent Cyano column, $3.5 \mu \mathrm{m}$ particle size, $150 \mathrm{~mm} \times 4.6 \mathrm{~mm}$ kept at $35^{\circ} \mathrm{C}$. The mobile phase consisted of phosphate buffer $25 \mathrm{mM}(\mathrm{pH}=3.0) / \mathrm{acetonitrile}$ $96: 4(\mathrm{v} / \mathrm{v})$. Flow rate, $0.6 \mathrm{ml} / \mathrm{min}$ and UV detection, $254 \mathrm{~nm}$. 
Table 1

Main validation parameters for acyclovir and guanine

\begin{tabular}{|c|c|c|c|c|c|c|}
\hline & \multirow{2}{*}{\multicolumn{2}{|c|}{$\begin{array}{l}\text { Quantification range } \\
\text { Acyclovir }\end{array}$}} & \multicolumn{4}{|c|}{ Impurities range } \\
\hline & & & \multicolumn{2}{|c|}{ Acyclovir } & \multicolumn{2}{|l|}{ Guanine } \\
\hline \multicolumn{7}{|l|}{ Standards linearity } \\
\hline Intercept & $-82=$ & & $0.37 \pm$ & & $0.28 \pm 0.34$ & \\
\hline Slope & 12762 & & 12804 & & $19019 \pm 37$ & \\
\hline$r$ & 0.999 & & 0.9999 & & 0.999998 & \\
\hline Range (mg/ml) & 0.304 & & 0.0002 & & $0.0002-0.0200$ & \\
\hline \multicolumn{7}{|l|}{ Sample linearity } \\
\hline Intercept & $-41=$ & & $0.29 \pm$ & & $0.11 \pm 0.29$ & \\
\hline Slope & 12632 & & 12795 & & $18763 \pm 31$ & \\
\hline$r$ & 0.999 & & 0.9999 & & 0.999996 & \\
\hline \multicolumn{7}{|l|}{ Accuracy $\%$ recovery } \\
\hline Standard & 99.99 & & 99.4 & & 98.4 & \\
\hline R.S.D. (\%) & 0.47 & & 1.8 & & 3.4 & \\
\hline Sample & 99.82 & & 98.7 & & 96.4 & \\
\hline R.S.D. (\%) & 0.18 & & 1.2 & & 6.7 & \\
\hline \multicolumn{7}{|c|}{ Standards precision instrumental } \\
\hline \multicolumn{7}{|c|}{ Intra-assay } \\
\hline Mean (mg/ml) & 0.39 & $n=10$ & 0.001 & $n=6$ & 0.002 & $n=6$ \\
\hline R.S.D. $(\%)$ & 0.30 & & 0.61 & & 0.23 & \\
\hline \multicolumn{7}{|l|}{ Intermediate } \\
\hline Mean (mg/ml) & 0.39 & $n=19$ & 0.001 & $n=12$ & 0.0002 & $n=12$ \\
\hline R.S.D. (\%) & 0.74 & & 1.3 & & 0.42 & \\
\hline \multicolumn{7}{|c|}{ Sample precision instrumental } \\
\hline \multicolumn{7}{|l|}{ Intra-assay } \\
\hline Mean (mg/ml) & 0.41 & $n=10$ & 0.001 & $n=6$ & 0.002 & $n=6$ \\
\hline R.S.D. $(\%)$ & 0.23 & & 0.69 & & 0.51 & \\
\hline \multicolumn{7}{|l|}{ Intermediate } \\
\hline Mean (mg/ml) & 0.41 & $n=20$ & 0.30 & $n=12$ & 0.002 & $n=12$ \\
\hline R.S.D. (\%) & 0.26 & & 0.88 & & 0.62 & \\
\hline \multicolumn{7}{|l|}{ Precision methods } \\
\hline \multicolumn{7}{|l|}{ Intra-assay } \\
\hline Mean (mg/ml) & 0.40 & $n=10$ & - & & - & \\
\hline R.S.D. $(\%)$ & 0.67 & & - & & - & \\
\hline \multicolumn{7}{|l|}{ Intermediate } \\
\hline Mean (mg/ml) & 0.40 & $n=20$ & - & & - & \\
\hline R.S.D. (\%) & 0.82 & & - & & - & \\
\hline
\end{tabular}

routine work. The final chromatogram of an acyclovir tablet at working conditions is shown in Fig. 7.

Validation has been performed following ICH guidelines [15-18] with standards and acyclovir tablets. Validation parameters are summarised in Table 1. Standards showed a good linearity as much for acyclovir in the quantification range as for acyclovir and guanine in the low range, with correlation coefficients over 0.999 . No bias was found in the regression lines, because the intercepts with their limits of confidence include the zero value. It must be pointed out that the objective of validating the method at impurity level for acyclovir was to use a dilution of the standard to quantify all the impurities different from guanine with the corresponding response factors, because these impurities are not usually available.
R.S.D. values were low enough to consider the method precise as much for standards as for acyclovir samples. Recoveries do not statistically differ from $100 \%$ ( $t$-test, $p<0.05$ ) in any case. Response factors are included in Table 2 for the different impurities related to acyclovir. They were very near

Table 2

Response factors for impurities relative to acyclovir

\begin{tabular}{ll}
\hline Analyte & Response factor \\
\hline Impurity A & 0.6974 \\
Impurity F & 1.1732 \\
Impurity Vir 3/4 & 0.9053 \\
Impurity N $^{7}$-diacetilacyclovir & 0.9459 \\
Impurity G & 0.9681 \\
\hline
\end{tabular}


to 1 , as the chromophore is very similar in all cases. Real limit of quantification of the method is the lower concentration value where it has been validated and therefore, it is $0.05 \%$ for all the compounds. The mathematical approach gave $0.004 \%$. Limits of detection were $0.001 \%$ for both acyclovir and guanine, which are under the necessary values for the method.

Finally, for stability of the standard the recovery after 3 days was $100.0 \%$ with a R.S.D. value of $0.83 \%$. Therefore, the standard can be considered stable for at least $72 \mathrm{~h}$ kept in solution at room temperature.

Although a formal robustness assay has not been achieved, this method has been applied over 6 months in a pharmaceutical formulations and it has always passed the system suitability test.

\section{Conclusions}

Agilent CN column has provided the development of a reversed phase HPLC method with UV detection. This column offers the separation of acyclovir, guanine and impurity A, under isocratic conditions and avoiding the employ of ionpairing reagents, in less than $15 \mathrm{~min}$ of total run and less than $40 \mathrm{~min}$ if four additional impurities are included in the measurement. Furthermore the geometry of the column employed presents lower dimensions that allowed a $40 \%$ saving of solvents when compared with classical columns.

The method has been validated and it has been shown that it is reliable, being linear, accurate and precise both in upper and lower concentration range. Therefore, it can be applied for quantification of the active compound and its impurities.

At last, the employment of a mobile phase adjusted at $\mathrm{pH}$ 1.8 , compatible with this kind of columns, permitted us also to evaluate the absence of impurity $\mathrm{C}$ that only appears in the synthetic process, assuring the selectivity of the method under lower aggressive conditions for the routine analysis.

\section{Acknowledgements}

We would like to thank Cinfa Laboratories for providing the test materials, Supelco and Agilent for providing the columns and VWR for the HPLC system.

\section{References}

[1] K. Balon, B.U. Riebesehl, B.W. Muller, Pharm. Res. 16 (1999) 882-888.

[2] K. Basavaiah, H.C. Prameela, Farmaco 57 (2002) 443-449.

[3] H.G. Daabees, Anal. Lett. 31 (1998) 1509-1522.

[4] M.S. Mahrous, M.M. Abdel Khalek, H.G. Daabees, Y.A. Beltagy, Anal. Lett. 31 (1992) 1491-1501.

[5] G.C.K. Battermann, S. Heizenroeder, D. Lubda, Labor Praxis 30 (1998) 32-34.

[6] Y. Pramar, V. Das Gupta, T. Zerai, Drug Dev. Ind. Pharm. 16 (1990) 1687-1695.

[7] S.S. Dubhashi, P.R. Vavia, Indian Drugs 37 (2000) 464-468.

[8] E. Kourany Lefoll, T.D. Cyr, Can. J. Appl. Spectrosc. 40 (1995) $155-159$.

[9] A.M. Kamel, P.R. Brown, B. Munson, Anal. Chem. 71 (1999) 5481-5492.

[10] D.S. Ashton, A. Ray, Anal. Proc. 30 (1993) 44-46.

[11] The Official Compendia of Standards, U.S. Pharmacopeia National Formulary, 2004

[12] I. Chappel, LC GC Int. 7 (1994) 282.

[13] K. Okusa, H. Tanaka, M. Ohira, J. Chromatogr. A 869 (2000) 143-149.

[14] W. Pleiderer, Ann. Chem. 647 (1961) 167.

[15] ICH, ICH Harmonised Tripartite Guideline, 1995, p. 1.

[16] ICH, ICH Harmonised Tripartite Guideline, 1996.

[17] ICH, ICH Harmonised Tripartite Guideline, 1996.

[18] ICH, ICH Harmonised Tripartite Guideline ICH topic Q2B, 1996. 